\title{
Immunological Study on Rift Valley Fever Virus among Human Beings in Taiz Governorate (Yemen)
}

\section{Al-Aesayi MSA ${ }^{*}$, Al-Helali MF¹, Mubarak JS², Al-Galibi SM${ }^{1}$ and Al- Qadasi $\mathrm{AM}^{3}$}

${ }^{1}$ Microbiology Division, Department of Biology, Faculty of Science, Sana'a University, Yemen

2Department of Biology, Faculty of Science, Sana'a University, Yemen

${ }^{3}$ Department of Laboratories, Faculty of Medicine, Hodeida University, Yemen

\section{Research Article \\ Volume 3 Issue 1}

Received Date: February 25, 2019

Published Date: March 04, 2019

*Corresponding author: Mansour Shayif Abdullah Al-Aesayi, Microbiology Division, Department of Biology, Faculty of Science, Sana'a University, Yemen, Tel: 00967-773458276; Email: abushaef@gmail.com

\section{Abstract}

Rift Valley Fever Virus (RVFV), which is transmitted to human beings by mosquitoes or direct contact with infected animals, is the etiologic agent of Rift Valley Fever (RVF). Using Enzyme Linked immunosorbent assay (ELISA), this study was performed to prepare RVFV antigen, which is used in detecting anti-RVFV antibodies, from liver of infected lambs. The study also aimed to study immunological prevalence of anti-RVFV IgM and IgG antibodies among human beings, which were conducted in the Research Center of Taiz University and Central Health Laboratory, Taiz Governorate, Southwestern Yemen. RVFV antigen was successfully prepared at a titer dilution of 1: 3200 by Chessboard (CB) ELISA assay. However, out of the 234 samples, 154 samples were positive for ELISA assay, of which 49 samples (31.8\%) were positive for anti-RVFV IgM and 105(68.2\%) were positive for anti-RVFV IgG antibodies. The antigen was successfully produced, and successfully adhered to ELISA plates. Simple and inexpensive methods gave good results. The result can be used to develop and refine predictive database for RVF transmission based on environmental and remote sensing data.

Keywords: Rift Valley fever; Antigen; ELISA; Immunology; Yemen

Abbreviations: RVFV: Rift Valley Fever Virus; RVF: Rift Valley Fever; ELISA: Enzyme Linked immunosorbent assay; IgM: Immunoglobulin M; IgG: Immunoglobulin G; rpm: Round Per Minute; CB: Chessboard; 3SD: three standard deviation.

\section{Introduction}

RVFV is the causative agent of RVF, a zoonotic disease, a member of the family Bunyavirridae, genus Phlebovirus, and an enveloped contains tri-segmented genome of single strand negative-sense RNA that affects both ruminants and human beings [1,2]. In ruminants, it induces almost $100 \%$ mortality among young animals and a high rate of abortion in pregnant females [3]. In human beings, the severity of infection can vary from mild to very severe clinical symptoms, including fever, blindness, encephalitis, and hemorrhagic fever with a fatal outcome $[3,4]$. It is transmitted to human beings by mosquitoes 


\section{Journal of Infectious Diseases \& Travel Medicine}

and through direct contact with tissues of infected animals or their products [5].

RVF is an endemic disease in Africa and the Arabian Peninsula. The outbreak appeared for the first time in Saudi Arabia and Yemen in 2000-2001. In Saudi Arabia, 11,882 human cases with 164 deaths were reported [6-8]. In Yemen, 1080 human cases with 141 deaths were reported [7-9], over 20.000 aborted animals with 620 dead $[7,10]$. Several outbreaks were followed after heavy rainfall in Egypt, Kenya, Somalia, Tanzania, Sudan, Mayotte, and Mauritania from 2003 to 2012 [11].

Several methods used in RVFV diagnosis. Scott, et al. [12] determined that the accuracy of serological methods in detecting anti-RVFV antibodies indicated that Enzyme Linked immunosorbent assay (ELISA) was the most precise serological method. So, this study aimed at preparing RVF antigen from liver of infected lamb to be used in detecting anti-RVFV antibodies by using indirect ELISA technique and studying immunological prevalence of anti-RVFV IgM and IgG antibodies among human beings as well as establishing primary database of RVF prevalence in Yemen.

\section{Materials and Methods}

A total of 234 people who suffered from fever, aged from 4 years to over than 50 years old, admitted in some hospitals of Taiz City, Southwestern Yemen, during the period from January 2013 until August 2016. About $5 \mathrm{ml}$ of blood were collected by venipuncture into sterile dry glass tube, labeled with a date, time of collection, the patient's name and number of sample, transferred to laboratory as soon as possible (within one hour) after the blood has been collected, allowed to clot for 30-45 min at room temperature, centrifuged at $2000 \mathrm{rpm}$ for $10 \mathrm{~min}$ for separation of serum, transferred into new sterile dry tube, capped tightly, labeled, inactivated in water bath at $56^{\circ} \mathrm{C}$ for $30 \mathrm{~min}$ for inactivation of complement, and stored in refrigerator at $-20{ }^{\circ} \mathrm{C}$ until used by ELISA. Accepted samples were clear, non-hemolyzed and nonlipemic, but rejected samples were excessive hemolysis, presence of large clots, leakage, microbial growth and repeated freeze-thaw cycles [12-14].

\section{Preparation of RVFV Antigen}

According to the information mentioned by Smithburn, et al. [15] the concentration of RVFV was highest in the liver of infected animal. Based on this data, RVFV antigen was prepared from a liver of lamb by using sucrose acetone extraction method according to the methods described by Clarke and Casals [16]. Lamb inoculation: under strict control measures, two lambs, aged 2 and 4 months, were inoculated intraperitoneally with $0.5 \mathrm{ml}$ of infected human serum by RVFV containing $10^{4} \mathrm{LD}_{50}$, which was kindly supplied by the Department of Virology, Central Researches laboratories, Taiz Governorate. Sufficient virus was present in serum of lambs after 4 days of inoculated, and the optimal titer dilution of virus in the serum was $1 / 1600$ when the lambs seemed unsteady gait. No one of the lambs died during the virus incubation period.

Procedure for preparing RVFV antigen: $10 \mathrm{~g}$ of the liver of the infected lamb was put in sterile mortar and thoroughly minced, four volumes of $8.5 \%$ aqueous solution of sucrose, after sterilized by filtration, were added to the liver tissue and mixed well until homogenized, and one volume of homogenate was added to $20 \mathrm{ml}$ of chilled acetone after vigorous shaking. Then, the tightly stoppered bottles were centrifuged at 1800 rpm for $5 \mathrm{~min}$ at $4^{\circ} \mathrm{C}$. The supernatant fluid was aspirated and chilled acetone equal to the aspirated amount was added to the sediment. The bottles were placed in an ice bath for at least one hour to dehydrate the gummy sediment. The centrifugation process was repeated twice, and the supernatant was aspirated and the sediment was completely dried by attaching a vacuum pump through a filter flask to the bottle containing the sediment. Normal saline was added to the dried sediment in a volume equal to 0.4 volume of the original volume of the homogenate. The sediment was dissolved within 2 hours and the solution was left overnight in a refrigerator. After a complete dissolving, the solution was centrifuged in a refrigerated centrifuge at 20,000 rpm for $30 \mathrm{~min}$. The supernatant containing the viral antigen was inactivated with binary, $20 \%$ sodium thaiosulphate solution sterilized by autoclaving, used to neutralize the 2-Bromoethylamine hydrobromide action, and then was kept in a bottle, frozen at $-70^{\circ} \mathrm{C}$ until used.

\section{Serological Examination}

Chessboard (CB) titration ELISA procedures for the prepared antigen was done according to Rose, et al. [17]. The prepared antigen was subjected to evaluation of the binding activity against specific antibody molecules IgM, IgG, and subjected to serial 2 -fold dilution in coating buffer, carbonate-bicarbonate buffer $\mathrm{pH} 9.6$ composed of $\mathrm{NaHCO}_{3} 2$.93g; $\mathrm{Na}_{2} \mathrm{CO}_{2}$ 1.59g; distilled $\mathrm{H}_{2} \mathrm{O} 1 \mathrm{~L}$, to obtain dilutions of $1: 50 ; 1: 100 ; 1: 200 ; 1: 400 ; 1: 800 ; 1: 1600$...etc. Row $\mathrm{H}$ was left empty as blank. $50 \mu \mathrm{l}$ of each dilution were dispensed into horizontal rows A-G wells in polystyrene microtiter plates (Maxisorp; Nunk, Copenhagen, Denmark, 
plates), incubated overnight at $4^{\circ} \mathrm{C}$, and washed 4 times by washing buffer $(0.5 \mathrm{ml}$ tween 20 in $1 \mathrm{~L}$ Phosphate buffer saline BPS which composed according to Voller, et al. [18] of $\mathrm{NaCl} 8.00 \mathrm{~g} ; \mathrm{KCl} 0.20 \mathrm{~g} ; \mathrm{KH}_{2} \mathrm{PO}_{4} 0.20 \mathrm{~g} ; \mathrm{Na}_{2} \mathrm{HPO}_{4} .12 \mathrm{H}_{2} \mathrm{O}$ 2.90g; distilled $\mathrm{H}_{2} \mathrm{O}$ 1L; pH 7.4). $50 \mu \mathrm{l} /$ well of blocking buffer, $10 \mathrm{~g}$ bovine serum albumin in $1 \mathrm{~L}$ BPS, were dispensed to all wells, incubated for $1 \mathrm{~h}$ at $37^{\circ} \mathrm{C}$ and washed 4 times. Two reference sera (strong positive and known negative) were diluted 2-fold 1:10; 1:20; $1: 40$ and so on in diluting buffer ( $5 \mathrm{~g}$ of bovine serum albumin; $50 \mu \mathrm{l}$ tween 20; in 1L BPS). 50 $\mu$ of each dilution were added to vertical columns (1-10) while the columns (11-12) received $50 \mu \mathrm{l}$ of the known negative serum sample, incubated at $37^{\circ} \mathrm{C}$ for $1 \mathrm{~h}$ in titer IgG or $2 \mathrm{~h}$ in IgM and washed 4 times. $50 \mu \mathrm{l}$ of diluted horseradish peroxidase conjugated goat anti-human IgG or swine anti- human IgM (Sigma Chemical Co.) were added to all wells, incubated $\left(1 \mathrm{~h}\right.$ in $\left.37^{\circ} \mathrm{C}\right)$, and washed 4 times. The substrate buffer, Citric acid (2.1g in $100 \mathrm{ml}$ distilled $\left.\mathrm{H}_{2} \mathrm{O}\right) 24.3 \mathrm{ml} ; \mathrm{Na}_{2} \mathrm{HPO}_{4}$ (7.1g in $100 \mathrm{ml}$ distilled $\mathrm{H}_{2} \mathrm{O}$ ) $25.7 \mathrm{ml}$; distilled $\mathrm{H}_{2} \mathrm{O} 50 \mathrm{ml}$; Orthophenylenediamine $40 \mathrm{mg} ; \mathrm{H}_{2} \mathrm{O}_{2} 20 \mu \mathrm{l}$, was added to all test wells $\left(50 \mu \mathrm{l} /\right.$ well), incubated at $37^{\circ} \mathrm{C}$ in dark place for $20 \mathrm{~min}$. $50 \mu \mathrm{l}$ of stopping buffer, $2.5 \mathrm{M}$ sulfuric acid $\left(\mathrm{H}_{2} \mathrm{SO}_{4}\right) ; \mathrm{pH} 3.3$, were added to all wells. The optical density was measured at $492 \mathrm{~nm}$ using plate readers. The highest dilution of antigen gave a value of 1.1 optical density (OD) after $20 \mathrm{~min}$ of substrate incubation with the strong positive serum antibodies IgG while gave a value of $1.2 \mathrm{OD}$ with the strong positive serum antibodies IgM, and under 0.1 OD with negative serum was considered the optimal dilution of the antigen.

ELISA procedures for detection of anti-RVFV IgM and IgG antibodies were done according to Voller, et al. [18]. The serum samples were analyzed for detecting antiRVFV IgM and IgG antibodies by using indirect ELISA assay. Ninety-six well polystyrene microtiter plates (Cooke M 29 AR; Dynatech plates) were coated with $100 \mu \mathrm{l} /$ well (Row H wells were left empty as blank) of RVFV antigen diluted in coating buffer, covered, incubated at $4^{\circ} \mathrm{C}$ overnight, and washed 3 times using washing buffer. $100 \mu \mathrm{l} /$ well of blocking buffer were dispensed to all wells, incubated for $1 \mathrm{~h}$ in moist chamber at $37^{\circ} \mathrm{C}$ for 30 min, and washed 3 times. Serum samples were diluted (1:10 for test IgG or 1:40 for IgM) in diluting buffer and $100 \mu \mathrm{l}$ of each serum sample were added in duplicate. Each plate included a positive control serum (wells A1-A6) and a negative control serum (wells A7-A12). Plates were incubated at $37^{\circ} \mathrm{C}$ for $1 \mathrm{~h}$ in test IgG or $2 \mathrm{~h}$ in IgM. After being washed 3 times, $100 \mu \mathrm{l}$ of horseradish peroxidase conjugate labeled goat anti-human IgG or swine antihuman IgM (whole molecules of IgG or IgM diluted according to the manufacturer's recommendation, Sigma
Chemical Co.) were added into each well, and incubated for $1 \mathrm{~h}$ at $37{ }^{\circ} \mathrm{C}$. The plates were washed 3 times and blotted on paper towels. $100 \mu \mathrm{l} /$ well of Orthophenylenediamine hydrochloride substrate were added and plates were left for $20 \mathrm{~min}$ at $37^{\circ} \mathrm{C}$ in dark. The reaction was stopped within $10 \mathrm{~min}$ after adding $50 \mu \mathrm{l}$ /well of stopping buffer. The plates were read by ELISA using dynastic plate reader at $492 \mathrm{~nm}$. The samples with optical density value more than 3SD above the mean of the negative control serum samples (Cutt-off) were considered positive.

$$
\text { Cutt-off }=\bar{X}+3 S D
$$

$\bar{X}=$ mean of negative control serum samples.

$\mathrm{SD}=$ standard deviation of negative control serum samples.

\section{Statistical Analysis}

Statistical analyses of the data were performed using statistical software package SPSS version 16. The categorical variables were done using Chi-square test at a $99 \%$ confidence level, and a significance level of 0.05 was used to determine the relationships between the data collection and immunological prevalence rates. Asymptotic Significance $\leq 0.05$ was considered to be significant.

\section{Ethical Approval}

Ethical approval for this study was granted by the Microbiology Division, Biology Department, Faculty of Science, Sana'a University Ethical Committee. Permission to conduct the study was given by Sana'a to Taiz Governorate authorities. Oral and written consents were obtained from all participants.

\section{Results}

Using specific IgM and IgG antibodies through CB ELISA titration assay, the antigen was successfully produced and titrated from liver of lamb. However, the highest titer dilution of antigen was investigated 1: 3200 by using CB titration ELISA assay for both IgM and IgG antibodies.

Out of the total 234 samples, $154(65.8 \%)$ of the cases were positive for ELISA assay, and $80(34.2 \%)$ were negative. However, the overall positive results rate was $49(31.8 \%)$ and $105(68.2 \%)$ for antibodies IgM and IgG respectively as shown in Table 1 . Regarding table 1 , the immunological prevalence rate of anti-RVFV IgM and IgG among human beings. Results revealed that the highest prevalence rate $56(36.4 \%)$ in age group 31-40 years was 
$20(13.0 \%)$ and $36(23.4 \%)$ of anti- RVFV IgM and IgG respectively. However, the overall prevalence rate of RVF cases $77(50.0 \%)$ was equally recorded in urban and rural patients. Noteworthy, the urban patients were equivalent in infection to the rural. The relationship among age groups, localities, and immunity response to IgM and IgG are not significant $>0.05$. In general, rate of males was higher than females. So, $97(63.0 \%)$ and
$57(37.0 \%)$ of patients were males and were more infected than females respectively. However, the highest immunological prevalence rate connected with patients' occupations was 65(42.2\%) in shepherds, who were more subjected to contact with animals. The relationship amongst sex, occupations, RVFV infection, and immunity response of the patients shows a statistical significant $\leq 0.05$.

\begin{tabular}{|c|c|c|c|c|c|c|}
\hline \multirow{3}{*}{ Variables } & \multicolumn{6}{|c|}{ ELISA assay of prepared antigen } \\
\hline & Anti-IgM & Anti-IgG & Total & \multirow{2}{*}{ P-Value } & \multirow{2}{*}{ df } & \multirow{2}{*}{ Asymp. Sig. } \\
\hline & No.(\%) & No.(\%) & No.(\%) & & & \\
\hline \multicolumn{7}{|c|}{ Age Groups } \\
\hline$<10$ & $0(0.00)$ & $2(1.3)$ & $2(1.3)$ & \multirow{6}{*}{0.396} & \multirow{6}{*}{1} & \multirow{6}{*}{0.529} \\
\hline Oct-20 & $2(1.3)$ & $13(8.4)$ & $15(9.7)$ & & & \\
\hline $21-30$ & $12(7.8)$ & $19(12.3)$ & $31(20.1)$ & & & \\
\hline $31-40$ & $20(13.0)$ & $36(23.4)$ & $56(36.4)$ & & & \\
\hline $41-50$ & $8(5.2)$ & $20(13.0)$ & $28(18.2)$ & & & \\
\hline$>50$ & $7(4.5)$ & $15(9.7 \%)$ & $22(14.3)$ & & & \\
\hline Total & $49(31.8)$ & $105(68.2)$ & $154(100)$ & & & \\
\hline \multicolumn{7}{|c|}{ Localities } \\
\hline Urban & $25(16.2)$ & $52(33.8)$ & $77(50.0)$ & \multirow{2}{*}{0.03} & \multirow{2}{*}{1} & \multirow{2}{*}{0.863} \\
\hline Rural & $24(15.6)$ & $53(34.4)$ & $77(50.0)$ & & & \\
\hline \multicolumn{7}{|c|}{ Sex } \\
\hline Males & $25(16.2)$ & $72(46.8)$ & $97(63.0)$ & \multirow{2}{*}{4.386} & \multirow{2}{*}{1} & \multirow{2}{*}{0.036} \\
\hline Females & $24(15.6)$ & $33(21.4)$ & $57(37.0)$ & & & \\
\hline \multicolumn{7}{|c|}{ Occupation } \\
\hline Shepherds & $13(8.4)$ & $52(33.8)$ & $65(42.2)$ & \multirow{3}{*}{12.78} & \multirow{3}{*}{1} & \multirow{3}{*}{0} \\
\hline Employee & $19(12.3)$ & $41(26.6)$ & $60(39.0)$ & & & \\
\hline Farmers & $17(11.0)$ & $12(7.8)$ & $29(18.8)$ & & & \\
\hline
\end{tabular}

Table 1: Immunological prevalence rate of anti-RVFV IgM and IgG among human beings in relation to socio-demographic characteristics.

No: Number of cases; Symp. Sig.: Asymptotic Significance; df: Degree of Freedom; P-Value: Possibility Value.

Actually, immunological prevalence rate of anti-RVFV IgM and IgG among human beings in relation to clinical symptoms and season is shown in Table 2 . Table 2 shows that headache had the highest distribution rate 105 (68.2\%) among IgM and IgG patients, decreased to 19(12.3\%) Vomiting and 16(10.4\%) Hemorrhagic fever among anti-IgM patients while Ocular diseases and Encephalitis had lowest distribution rate 8(5.2\%) and 6 (3.9\%) among anti-IgG patients respectively. The relationship between clinical symptoms and immunity response is significant $\leq 0.05$. However, the results revealed that the highest immunological distribution rate demonstrably appeared 64(41.6\%) in Summer and, decreased to 56(36.4\%) in Autumn. Therefore, the prevalence rate decreasingly started at end of Autumn and dramatically increased at end of Spring. The relationship among immunity response for the patients, RVFV infection, and seasons of year doesn't have a statistically significant $>0.05$.

\begin{tabular}{|c|c|c|c|c|c|c|}
\hline \multirow{3}{*}{ Variables } & \multicolumn{6}{|c|}{ ELISA assay of prepared antigen } \\
\hline & Anti-IgM & Anti-IgG & Total & \multirow{2}{*}{ P-Value } & \multirow{2}{*}{ Df } & \multirow{2}{*}{ Asymp. Sig. } \\
\hline & No. $(\%)$ & No. $(\%)$ & No. $(\%)$ & & & \\
\hline \multicolumn{7}{|c|}{ Clinical symptoms } \\
\hline Headache & $19(12.3)$ & $86(55.8)$ & $105(68.2)$ & \multirow{3}{*}{3.819} & \multirow{3}{*}{1} & \multirow{3}{*}{0.051} \\
\hline Vomiting & $16(10.4)$ & $3(1.9)$ & $19(12.3)$ & & & \\
\hline Hemorrhagic fever & $14(9.1)$ & $2(1.3)$ & $16(10.4)$ & & & \\
\hline
\end{tabular}




\section{Journal of Infectious Diseases \& Travel Medicine}

\begin{tabular}{|c|c|c|c|c|c|c|}
\hline Ocular diseases & $0(00.0)$ & $8(5.2)$ & $8(5.2)$ & & & \\
\hline Encephalitis & $0(00.0)$ & $6(3.9)$ & $6(3.9)$ & & & \multirow{2}{*}{0.16} \\
\hline \multicolumn{7}{|c|}{ Season } \\
\hline Summer & $23(14.9)$ & $41(26.6)$ & $64(41.6)$ & & & \multirow{2}{*}{1.973} \\
\hline Autumn & $19(12.3)$ & $37(24.0)$ & $56(36.4)$ & & \\
\hline Winter & $0(00.0)$ & $4(2.6)$ & $4(2.6)$ & & & \\
\hline Spring & $7(4.5)$ & $23(14.9)$ & $30(19.5)$ & &
\end{tabular}

Table 2: Immunological prevalence rate of anti-RVFV IgM and IgG among human beings in relation to clinical symptoms and season.

No.: Number of cases; Symp. Sig.: Asymptotic Significance; df: Degree of Freedom; P-Value: Possibility Value.

\section{Discussion}

This study was performed to prepare RVFV antigen from lamb liver to be used in detecting anti-RVFV antibodies in human beings or animals' serum samples by using modern ELISA technique and to study immunological prevalence of anti-RVFV IgM and IgG among human beings.

The prepared antigen from lamb liver was successfully prepared using sucrose acetone extraction technique and also assessed successfully by IgM and IgG antibodies. This antigen was successfully adhered to CB ELISA plates directly at a high titer dilution of 1: 3200 . This result is in consistence with those recorded by Said, et al. [19], who produced same antigen from the liver of sheep at a dilution of 1:200. Similar antigen prepared by Paweska, et al. [20] from infected mouse liver at a dilution of 1:400. Moreover, Mysa, et al. [21] prepared RVFV antigen from the liver of hamster at a dilution of 1:3200. From the mentioned above, the difference in titration results may be related to variance in methods of test, accuracy and sensitivity of test.

The present study showed that 154 out of 234 cases were positive for ELISA assay. Their ages ranged from 4 years to over than 50 years. Nearly similar to those obtained in Egypt, the Kingdom of Saudi Arabia, Nigeria, Kennya, Somalia, and Mauritania by Olaleye, et al. [22], Nabeth, et al. [23], Seleem, et al. [8], Woods, et al. [24], Tariq, et al. [4], Youssef [25].

The overall immunological prevalence rate of antiRVFV IgM was $31.8 \%$. This is similar to those obtained by MMWR [26] recorded 33.4\% in Egypt, and is nearly similar to those reported by Sarthou, et al. [27] and Olaleye, et al. [22] during their survey in Mauritania and Nigeria whose findings were $24.3 \%$ and $23.2 \%$ respectively. The highest immunological prevalence rate $13.0 \%$ was in the age group ranging from 31-40 years. This is in agreement with MMWR [26], Olaleye, et al. [22],
Tariq, et al. [4], Memish, et al. [28] whose results were similar or with slightly lower percentages, and may be referred to individuals with ruminant exposure, or patients with specific age groups, variance in sample size, specificity of test and low concentration of the antibodies in the serum samples.

Moreover, the overall immunological prevalence rate of anti-RVFV IgG was $68.2 \%$. In contrary to this, lower findings were reported by MMWR [26], Thonnon, et al. [29] Nabeth, et al. [23], Seleem, et al. [8], Woods, et al. [24], Youssef, et al, [25], Mysa, et al. [21], Memish, et al. [28], Tigoi, et al. [30] whose records $13 \%, 15.3 \%, 24.4 \%$, $10.6 \%, 15 \%, 10.3 \%, 10.53 \%, 11.1 \%$ and $19.5 \%$ respectively. The difference in results may be resulted because we collected our samples from patients with acute RVF infection. The results also revealed that the highest prevalence rate $23.4 \%$ was in the age group ranging from $31-40$ years. This finding is in a disagreement with previous studies in Egypt by Youssef, et al. [25], Mysa, et al. [21] who recorded lower rate of $13.7 \%$ in the age group 31-40 years. Therefore, there was a significant difference between age groups and immunity response of human beings $>0.05$.

Regarding Localities, the overall distribution rate of RVF cases 77(50.0\%) in urban areas was similar to those in rural areas $77(50.0 \%)$. On the other hand, lower percentages of $13.6 \%, 11.8 \%$ in rural areas and $5.3 \%, 8.7 \%$ in urban one was previously recorded by Seleem, et al. [8], Mysa, et al. [21] respectively. From the mentioned above, we find that the distribution rate $25(16.2 \%)$ and $24(15.6 \%)$ of anti-RVFV IgM is similar to $52(33.8 \%)$ and $53(34.4 \%)$ of anti-RVFV IgG in rural and urban areas respectively. This may be attributed to many predisposing factors such as presence of animal reservoir, agricultural activities, irrigation, and people sleeping on the roofs of buildings in Summer. There was also a significant difference between Localities and immunity response of human beings $>0.05$, but it showed important with Pvalue 0.030 . 
Obviously, the overall immunological prevalence rate in males and females was 97(63.0) and 57(37.0\%) respectively. The higher percentages in males than females may be attributed to that males are repeatedly exposed to mosquito more than the females during sleep outdoors. The obtained results are in agreement with Woods, et al. [24]. The prevalence rate of anti-IgM cases was similar 25(16.2) and 24(15.6) in males and females respectively while the prevalence rate of anti-IgG was higher $72(46.8 \%)$ in the males than the females $33(21.4 \%)$. This result may be attributed to the fact that males are more involved than females in occupations that require direct contact with susceptible animals and the infectious agents Turell, et al. [31]. This result is in agreement with Woods, et al. [24], Seleem, et al. [8], Youssef [25], Mysa, et al. [21], Byomi, et al. [32]. There was a statistical significant amongst gender, RVFV infection, and immunity response of human beings $<0.05$.

The highest prevalence rate $65(42.2 \%)$ was in shepherds while it decreased to $29(18.8 \%)$ in Farmers. This result may be attributed to that shepherds contacted with susceptible animals many times, while the farmers only contacted with breeding habitats of mosquitoes. These results are in consistence with those reported in Mauritania by Boushab, et al. [11] who recorded lower prevalence rate $26 \%$ in shepherds and $3 \%$ in farmers. There was also a statistical significant between occupations and immunity response of human beings < 0.05 .

The most common symptoms were $12.3 \%, 10.4 \%$ and $9.1 \%$ of anti-IgM accompanied with headache, vomiting and Hemorrhagic fever while the lowest prevalence was $5.2 \%$ and $3.9 \%$ of anti-IgG accompanied with Ocular diseases and encephalitis respectively. This is in agreement with Tariq, et al. [4], Arthur, et al. [33], Woods, et al. [24]. who recorded similar prevalence rate? There was a statistical significant among symptoms of disease, RVFV infection, and immunity response of human beings $<0.05$.

The highest immunological prevalence rate recorded $14.9 \%$ and $26.6 \%$ in Summer and followed by $12.3 \%$ and $24.0 \%$ in Autumn of anti-RVFV IgM and IgG respectively. These findings are in agreement with Olaleye, et al. [22] who mentioned that the infection rate was significantly higher during the wet season than during the dry season of the same year. This is in consistence with Mysa, et al. [21], who recorded lower prevalence rate of anti-IgG was $20 \%$ in Summer, $7.14 \%$ in Autumn. The difference in results may be attributed to the environmental factors, vegetation, rainfall, slope degree, abundance of vectors, and selected specimens. There was a significant difference between seasons of year and immunity response of human beings $>0.05$.

\section{Conclusion}

The prepared antigen was successfully produced and adhered to ELISA plates at a highest titer dilution of 1 : 3200 . Simple and inexpensive methods gave good results. The overall positive results rate $154(65.8 \%)$ was positive for antibodies IgM and IgG. Immunological prevalence of RVF among human beings would be the highest in Autumn and in Summer, especially during rainfall and Greater Feast. People aged between 31-40 years are the most infected, and males are more infected than females. The result can be used to develop and refine predictive database for RVF transmission based on environmental and remote sensing data.

\section{Acknowledgements}

We would like to thank members of Microbiology Department in both Sana'a and Taiz University, Yemen, for their support, and crew of Central Public Health Laboratory and Environment Protection agency, Taiz Governorate, Yemen, for their cooperation, and all who contributed in this study.

\section{Funding Information}

There are no existed financial competing interests. The views expressed here by belong to the authors and not necessarily belong to the funding bodies.

\section{Conflicts of Interest}

There are no personal or professional conflicts of interest.

\section{References}

1. Mansfield KL, Banyard AC, McElhinney L, Johnson N, Horton DL, et al. (2015) Rift Valley Fever virus: A review of diagnosis and vaccination, and implications for emergence in Europe. ScienceDirect 33(42): 55205522.

2. Bouloy M, Weber F (2010) Molecular biology of Rift Valley Fever Virus. Open Virology J 4: 8-14.

3. Laughlin LW, Meegan JM, Strausbaugh LW, Morens DM, Watten RH (1979) Epidemic Rift Valley fever in Egypt, observation of the spectrum of human illness. Trans R Soc Trop Med Hyg 73(6): 630-633. 


\section{Journal of Infectious Diseases \& Travel Medicine}

4. Tariq A, Madani YY, Al-Mazrou MH, Al-Jeffri AA, Mishkhas AM, et al. (2003) Rift Valley Fever Epidemic in Saudi Arabia: Epidemiological, Clinical, and Laboratory Characteristics. Clinical Infectious Diseases 37(8): 1084-1092.

5. Elizabeth Cook, Grossi-Soystter EN, de Glanville WA, Thomas LF, Kariuki S, et al. (2017) The seroepidemiology of Rift Valley Fever in people in the lake Victoria basin of western kenya. PLoS Negl Trop Dis 11(7): e0005731.

6. Pepin M, Bouloy M, Bird BH, Kemp A, Paweska J (2010) Rift valley fever virus (Bunyaviridae: Phlebovirus): an update on pathogenesis, molecular epidemiology, vectors, diagnostics and prevention. Vet Res 41(6): 60-63.

7. Chaniotis B (2003) Arthropod-borne viral zoonoses in the Mediterranean area (An overview). Information circular-WHO Mediterranean Zoonoses Control Center 56: 1-16.

8. Seleem MN, Asmaa Hussein, Ismail AA, Nafie EK (2002) Serological studies on RVF in some patients of fever hospital in Upper Egypt. J Egypt Vet Med Assoc 62(6a): 261-271.

9. WHO (2000) World Health Organization. Rift Valley fever outbreak., Disease Outbreak Reported, Global Alert and Response (GAR), pp: 1-44.

10. Abdo-Salem AS, Waret-Szkuta A, Roger F, Olive MM, Saeed K, et al. (2011) Rift valley fever in Yemen. Trop Anim Health Prod 43(2): 471-480.

11. Boushab MB, Fatima Zahra, Sidi WOB, Mohamed LOS, Marie Roseline DB, et al. (2016) Sever human illness caused by Rift Valley Fever Virus in Mauritania. Oxford University Press, Open Forum Infect Dis 3(4): ofw200.

12. Scott RM, Feinsod FM, Allam IH, Ksiazek TG, Peters CJ, et al. (1986) Serological tests for detecting Rift Valley fever viral antibodies in sheep from the Nile Delta. J Clin Microbiol 24(4): 612-614.

13. Burleson FG, Chambers TM, Wiedbrauk DL (1992) Virology: a laboratory manual. 2nd $(E d n)$, Academic Press San Diego, Sydney.

14. Provenzano M, Rossi CR, Mocelline S (2001) The usefulness of quantitative Real time PCR in immunogenetics. ASHI quarterly, Third quarter, pp: 1-3.
15. Smithburn KC, Haddow AJ, Lumsden WHR (1949) Rift Valley Fever; Transmission of the virus by mosquitoes. Br J Exp Pathol 30(1): 35-47.

16. Clarke DH, Casals J (1958) Techniques for hemagglutination and hemagglutination-inhibition with arthropod-borne viruses. Am J Trop Med Hyg 7(5): 561-573.

17. Rose NR, Friedman H, Fahey JL (1986) Manual clinical laboratory immunology, $3^{\text {rd }}$ (Edn). American Society for Microbiology, pp: 107-109.

18. Voller A, Bidwell D, Bartlett A (1976) Microplate enzyme immunoassays for the immunodiagnosis of virus infection. Am Soc for Microbiology pp: 506-512.

19. Said, Taradi Abd El fatah (2003) Production of some diagnostic reagents for Rift Valley fever.

20. Paweska JT, Barnard BJ, Williams R (1995) The use of sucrose acetone extracted RVFV antigen derived from cell culture in an indirect Elisa and HI. Onderstepoort J Vet Res 62(4): 227-233.

21. Mysa Awadallah (2006) Some epidemiological studies on Rift Valley Fever.

22. Olaleye OD, Tomori O, Ladipo MA, Schmitz H (1996) Rift Valley fever in Nigeria: infection in humans. Rev Sci Tech 15(3): 923-935.

23. Nabeth $P$, Kane $Y$, Abdalahi Mo, Diallo M, Ndiaye $K$, et al. (2001) Rift Valley Fever outbreak, Mauritania, 1998: Seroepidemiologica, Virologica, Entomologic and Zoologic investigation. Emerg Infect Dis 7(6): 1052-1054.

24. Woods CW, Karpati AM, Grein T, McCarthy N, Gaturuku P, et al. (2002) Hemorrhagic Fever Task Force. An Outbreak of Rift Valley Fever in Northeastern Kenya, 1997-98. Emerging Infectious Diseases 8(2): 138-144.

25. Youssef AI (2004) An epidemiological study on RVF in Ismailia province.

26. MMWR (1994) Morbidity and Mortality Weekly Report. Rift Valley Fever-Egypt 43(38): 693-700.

27. Sarthou JL, Jouan A, Le Guenno B, Philip B, Rio O, et al. (1989) Isolation of RVFV from human peripheral blood mononuclear cells. Mauritanian epidemic. Res Virology 140(3): 263-270. 
28. Memish ZA, Masri MA, Anderson BD, Merrill HR, Khn SU, et al. (2015) Elevated antibodies against Rift Valley fever virus among humans with exposure to ruminants in Saudi Arabia. Am J Trop Med Hyg 92(4): 739-743.

29. Thonnon J, Picquet M, Thiongane $Y$, Mustapha LO, Sylla R, et al. (1999) RVF surveillence in the lower Senegal River basin: update 10 years after the epidemic. Trop Med International Health 4(8): 580585.

30. Tigoi C, Lwande O, Orindi B, Irura Z, Ongus J, et al. (2015) Seroepidemiology of selected arboviruses in febrile patients visiting selected health facilities in the lake/river basin areas of lake Baringo, lake Naivasha, and Tana River, Kenya. Vector Borne Zoonotic Dis 15(2): 123-132.

31. Turell MJ, Linthicum KJ, Beaman JR (1990) Transmission of Rift Valley fever virus by adult mosquitoes after ingestion of virus as larvae. Am J Trop Med Hyg 43(6): 677-680.

32. Byomi AM, Samaha HA, Zidan SA, Hadad GA (2015) Some associated risk factors with the ocurrence of Rift Valley fever in animals and man in certain localities of Nile Delta, Egypt. Assiut Vet Med J 16(61): 144.

33. Arthur RR, El-sharkawy MS, Cope SE, Botros BA, Oun $S$, et al. (1993) Recurrence of Rift Valley Fever in Egypt. Lancet 342(8880): 1149-1150. 